\title{
Maslinic Acid Activates Renal Ampk/sirt1 Signaling Pathway to Protect Against Diabetic Nephropathy in Mice
}

\section{Huijuan Gao}

Daqing Oilfield General Hospital

Hong Wu ( $\nabla$ wh780909@163.com )

Daqing Longnan Hospital

\section{Research Article}

Keywords: Maslinic acid, diabetic nephropathy, AMPK/SIRT1 signaling, Glomerulus

Posted Date: July 29th, 2021

DOl: https://doi.org/10.21203/rs.3.rs-668934/v1

License: (c) (1) This work is licensed under a Creative Commons Attribution 4.0 International License.

Read Full License 


\section{Abstract}

\section{Background}

Diabetic nephropathy has been a devastating complication. Clinically, there is an urgent need for nephroprotective agents to delay the onset of diabetic nephropathy and ameliorate its symptoms. Maslinic acid is a pentacyclic triterpene acid with protective effect on multiple organs from oxidative stress and inflammation. However, the therapeutic effect of maslinic acid on diabetic nephropathy remains unclear.

\section{Methods}

C57BL/6J male mice administrated with $50 \mathrm{mg} / \mathrm{kg}$ of Streptozocin (STZ) daily were used to establish diabetic mouse model (blood glucose levels $>300 \mathrm{mg} / \mathrm{dL}$ ). Urinary levels of albumin, total proteins, and creatinine were analyzed by an automatic analyzer. H\&E staining was used to evaluate renal damage. qRT-PCR and ELISA assay were performed to investigate the inflammation and oxidative stress of renal tissues. Western-blotting assay was used to demonstrate the activation of AMPK signaling.

\section{Results}

Maslinic acid treatment alleviated the loss of body weight and blood glucose in diabetic mice. The renal structure and function were protected by maslinic acid in diabetic mice. $20 \mathrm{mg} / \mathrm{kg}$ maslinic acid treatment for 8 weeks alleviated the oxidative stress and inflammation in the kidney of diabetic rats dramatically. Maslinic acid treatment activated renal AMPK/SIRT1 signaling.

\section{Conclusion}

Maslinic acid ameliorated diabetic nephropathy via activating AMPK/SIRT1 signaling pathway.

\section{Introduction}

Diabetic nephropathy is a main chronic microvascular complication of diabetes [1]. Chronic high blood glucose levels and systemic metabolic abnormalities caused by diabetes lead to glomerulosclerosis and kidney damage [2]. Therefore, diabetic nephropathy is a component of diabetic systemic microangiopathy [3]. Diabetic nephropathy has been a leading cause of chronic kidney disease (CKD) and end-stage renal disease (ESRD) [4]. At present, approximately $45 \%$ of ESRD patients in the United States suffer from diabetic nephropathy [5]. Diabetic nephropathy increases the morbidity and mortality of cardiovascular disease in diabetic patients $[6,7]$. Therefore, it is urgent for us to identify new agents to alleviate the symptoms of diabetic nephropathy and protect the renal function of diabetes patients.

Maslinic acid is a pentacyclic triterpene acid and a major bioactive component of Chinese traditional herbs including hawthorn, olive and red dates $[8,9]$. The various pharmacological activities of maslinic acid, including anti-cancer, anti-oxidation, anti-virus, anti-bacterial, anti-cancer activities, have attracted 
great attention from the medical community [10-12]. It has also been reported that maslinic acid can inhibit the apoptosis and necrosis of renal cells, protect the structure and function of the glomerulus, and thus have a therapeutic effect on the nephrotoxicity caused by cisplatin in rat model $[13,14]$. In addition, accumulating evidence has demonstrated that maslinic acid alleviates the symptoms of diabetes and reduces the damage of the heart and liver caused by diabetes $[15,16]$. However, the protective effect of maslinic acid in diabetic nephropathy and the underlying molecular mechanism remain unclear.

Adenosine 5'-monophosphate (AMP)-activated protein kinase (AMPK) is an important cell energy sensor, which is highly expressed in mesangial cells, glomerular endothelial cells and podocytes [17]. AMPK induces the activation of the insulin receptor tyrosine kinase, which in turn leads to the phosphorylation of its downstream substrate proteins. Therefore, AMPK is a positive regulator of insulin sensitivity, which plays a crucial role in regulating glucose uptake, enhancing insulin sensitivity, increasing fatty acid oxidation and regulating gene transcription [18]. Previous research has demonstrated that AMPK specific activation could reduce podocyte damage, maintain the integrity of the glomerular filtration barrier, and prolong the occurrence of diabetic nephropathy [17].

In this research, we reported that maslinic acid activated AMPK/SIRT1 signaling pathway to protect renal function against diabetic nephropathy. $20 \mathrm{mg} / \mathrm{kg}$ maslinic acid treatment for 8 weeks repressed the oxidative stress and inflammation in kidney of diabetic mice. We believed that our research could provide new evidence for the clinical applications of maslinic acid to treat diabetic nephropathy.

\section{Methods}

\section{Animals}

C57BL/6J mice between 16 to $22 \mathrm{~g}$ (aged 4-6 weeks) were purchased from Animal Model Research Center. Streptozocin (STZ, Sigma Aldrich, MO, USA) was used to induce diabetic mouse model. A $0.1 \mathrm{~mol} / \mathrm{L}$ sodium citrate solution was used to prepare a $10 \mathrm{mg} / \mathrm{ml} \mathrm{STZ} \mathrm{solution.} \mathrm{Fresh} \mathrm{STZ} \mathrm{solution} \mathrm{was}$ configured in a dark room and filtered with a $0.22 \mu \mathrm{M}$ filter. $50 \mathrm{mg} / \mathrm{kg}$ of STZ was injected intraperitoneally into mice for 5 days in a row for diabetes induction, and the same amount of sodium citrate solution was used as negative control. Fasting blood glucose levels $>300 \mathrm{mg} / \mathrm{dL}$ was regarded as the incidence of diabetes. Carbon dioxide euthanasia was used for sacrifice of mice. The mice were placed in a PC box statically, and the $\mathrm{CO} 2$ flow rate was adjusted to $10 \mathrm{~L} / \mathrm{min}$. The cylinder valve was closed about 7 minutes after the carbon dioxide filled the container. Only mice without breathing and heartbeat could be removed from the PC box. The study was reported in accordance with Animal Research: Reporting of In Vivo Experiments (ARRIVE) guidelines. The methods were performed in accordance with the relevant guidelines of the institutional animal care and use committee of Daqing Oilfield General Hospital.

\section{Experiment design}


Diabetic mice of similar body weight were randomized in four groups: STZ (control group), MA5 (5 mg/kg maslinic acid), MA10 (10 mg/kg maslinic acid), and MA20 (20 mg/kg maslinic acid). Normal control (NC). Maslinic acid (MedChemExpress, Beijing, China) was injected intraperitoneally every 3 days after diabetes induction for 8 weeks. The changes in body weight and fasting glucose levels of mice were respectively evaluated.

\section{Serum, urine, and renal tissue collection}

The mice were kept in special metabolic cages (LaiAT technology co., LTD, Beijing, China) at the end of maslinic acid treatment for 24 hours to collect their urine. Their urine volume was measured immediately and all urine samples were kept at $-20^{\circ} \mathrm{C}$ for further analysis. Next, mice after $4 \mathrm{~h}$-fasting were anesthetized with $50 \mathrm{mg} / \mathrm{kg}$ pentobarbital sodium. The blood of each mice was collected by the capillary needle through their eyeball. Blood samples were centrifuged at 5,000 rpm for $10 \mathrm{~min}$ at room temperature to collect serum. All serum samples were frozen at $-20^{\circ} \mathrm{C}$ for further analysis. Finally, mice were sacrificed by cervical dislocation method, and their kidney were removed and kept on ice. Their renal tissues were stored at $-80^{\circ} \mathrm{C}$.

\section{H\&E staining}

Removed tissue block (generally no more than $0.5 \mathrm{~cm}$ thick) was put into a fixative (Bouin's fixative) to denature and coagulate the protein of the tissue and cells. Alcohol were used to dehydrate tissue mass. Transparent tissue block was placed in the melted paraffin and put into the melting wax box for heat preservation. Embedded wax block was fixed on microtome and cut into thin slices. Hematoxylin and eosin were used for cell staining in accordance with the operating procedures.

\section{Serum and urine parameters}

An automatic analyzer was used for serum parameters including fasting blood glucose, blood urea nitrogen (BUN), urea, Creatinine, and urine parameters including urine albumin, urine total protein, urine Creatinin. The analysis and calculation were previously demonstrated by Ali A. Shati and Zhang. et. Al [16], and the measurement were done for $\mathrm{n}=14$ per group.

\section{Oxidative biomarkers measurement}

The biomarkers of oxidative stress including malondialdehyde (MDA) (Abcam, Shanghai, China), Reactive oxygen species (ROS) (Abcam, Shanghai, China), Manganese superoxide dismutase (MnSOD) (Shizebiotec company, Shanghai, China) and glutathione (GSH) (Beyotime, Shanghai, China) were evaluated by commercial kits

\section{ELISA assay}

According to the manufacturer's protocol, an ELISA assay was performed to prove the cytokine levels in the mouse serum. TNF-a, IL-6, and MCP-1 in mouse serum were measured by commercially available kits.

\section{Quantitative real-time PCR}


The mouse lung tissue homogenate was mixed with $1 \mathrm{~mL}$ Trizol. Chloroform and isopropanol were used to extract RNA from tissues in accordance with standard procedures. The cDNA reverse transcription kit was used to reverse transcribe RNA into CDNA according to the procedure in the instructions. SYBR green was used as the fluorescent signal during the qRT-PCR reaction. GAPDH was used as a negative control. The primers used in this study are as follows:

IL-6F, 5'-ACAACCACGGCCTTCCCTACTT-3',

R, 5'-CACGATTTCCCAGAGAACATGTG-3';

TNF-aF, 5'-CTACCTTGTTGCCTCCTCTTT-3',

R, 5'-GAGCAGAGGTTCAGTGATGTAG-3';

MCP-1 F, 5'- TAAAAACCTGGATCGGAACCAAA-3',

R, 5'- GCATTAGCTTCAGATTTACGGGT-3'.

GAPDHF 5'-ACCCCAGCAAGGACACTGAGCAAG-3',

R 5'-GGCCCCTCCTGTTATTATGGGGGT-3'.

\section{Western-blotting assay}

After tissue grinding, RIPA lysate was added to extract the protein. The protein concentration was determined by the BCA method. $2 \times$ protein loading buffer was added into the protein mixture according to the volume ratio. Samples were placed in a heater for denaturation for 10 minutes and stored in $-80{ }^{\circ} \mathrm{C}$. The samples were separated by SDS-polyacrylamide constant pressure gel electrophoresis, and the protein was transferred to the PVDF membrane (Millipore, USA) by the wet transfer method at $300 \mathrm{~mA}$ for 90 min. The PVDF membrane was placed in 10\% skimmed milk powder-TBST and sealed at room temperature for 1 hour. The primary antibody with working solution (5\% BSA-TBST configuration) including anti-p-AMPK, anti-AMPK, anti-SIRT1 and anti-actin (1:1000, Cell Signaling Technology, Beijing, China) were incubated with specific membrane at $4^{\circ} \mathrm{C}$ overnight. On the second day, the PVDF membrane was washed by PBS at room temperature for $10 \mathrm{~min} \times 3$ times. HRP-labeled secondary antibody (1: 800, Beijing Zhongshan) was incubated with membrane for 1 hour at room temperature. ECL luminescent substrate was used for blot imaging.

\section{Statistical analysis}

Categorical variables were displayed as frequency or percentage. We used the mean and standard deviation to prove continuous variables. In this study, Student test and one-way ANOVA test were used for statistical analysis with mean \pm SD or SEM. $P<0.05$ and $p<0.01$ were regarded as significant differences.

\section{Results}


To demonstrate the potential therapeutic effects of maslinic acid on diabetes, body weight, fasting blood glucose levels, average food intake and average water intake were measured and analyzed. As shown in Fig. $1 \mathrm{a}, 20 \mathrm{mg} / \mathrm{kg}$ maslinic acid treatment significantly rescued the body-weight loss induced by STZ administration. Similarly, $5 \mathrm{mg} / \mathrm{kg}, 10 \mathrm{mg} / \mathrm{kg}$ and $20 \mathrm{mg} / \mathrm{kg}$ maslinic acid treatment markedly decreased the fasting blood glucose levels compared to the STZ group (Fig. 1b). In addition, $20 \mathrm{mg} / \mathrm{kg}$ maslinic acid significantly lowered the food and water intake in diabetic mice (Fig. 1c and d). Totally, administration of different amounts of maslinic acid alleviated the symptoms of diabetic mice to varying degrees, and there were no significant side-effects of maslinic acid on diabetic mice. Accordingly, we chose $20 \mathrm{mg} / \mathrm{kg}$ as the dosage for long-term maslinic acid administration.

\section{Effects of maslinic acid on serum parameters in diabetic mice.}

To investigate the effects of maslinic acid administration on the renal function, kidney/body weight, Urea, BUN and Creatinine in serum of mice with diabetic nephropathy was measured by an automatic analyzer ( $N=14$ per group). As shown in Fig. 2a, STZ treatment induced the renal fibrosis and the increase of kidney/body weight ratio. On the other hand, $20 \mathrm{mg} / \mathrm{kg}$ maslinic acid treatment significantly rescued the increased kidney/body weight ratio, suggesting that maslinic acid protected the nephron of mice with diabetic nephropathy from sclerosis. Similarly, $5 \mathrm{mg} / \mathrm{kg}, 10 \mathrm{mg} / \mathrm{kg}$ and $20 \mathrm{mg} / \mathrm{kg}$ maslinic acid treatment induced the decrease of serum urea, BUN and creatinine levels to varying degrees (Fig. 2b, c and d), suggesting that maslinic acid administration protect the renal function of mice with diabetic nephropathy.

\section{Effects of maslinic acid on urine parameters in diabetic mice.}

To further demonstrate the nephroprotective role of maslinic acid in diabetic nephropathy, urine parameters including urine volume, urine albumin, total proteins and creatinine of diabetic mice after 8week maslinic acid treatment were measured and analyzed respectively. As shown in Fig. 3a, maslinic acid treatment alleviated the polyuria in diabetic mice induced by STZ. More importantly, maslinic acid treatment significantly lower albumin and total protein in the urine of diabetic mice, suggesting that maslinic acid protected the function of glomerulus in diabetic nephropathy (Fig. $3 \mathrm{~b}$ and c). In addition, maslinic acid treatment also induced the increase of creatinine in urine of mice with diabetic nephropathy (Fig. 3d), indicating that maslinic acid ameliorated the filtration function of the kidney.

\section{Effects of maslinic acid treatment on renal injury.}

As shown in Fig. 4a and 4b, STZ induced mice showed an upregulation in the mass of glomerulus epithelium, thicker Bowman's capsule, enhanced vacuolization in both the proximal and distal tubules, and much more arteriolopathy. On the other hand, $20 \mathrm{mg} / \mathrm{kg}$ maslinic acid treatment for 8 weeks protected the normal structure of glomeruli and tubules. $20 \mathrm{mg} / \mathrm{kg}$ maslinic acid treatment significantly ameliorated the renal injury induced by diabetes in mice. 
To further investigate the mechanisms for maslinic acid to inhibit the renal injury induced by STZ, the oxidative biomarkers including MDA, ROS, MnSOD, GSH and CAT were measured. As shown in Fig. 5a and b, $20 \mathrm{mg} / \mathrm{kg}$ maslinic acid treatment for 8 weeks induced the down-regulation of MDA and ROS levels in renal tissues in diabetic mice, suggesting that maslinic acid decreased the oxidative stress in the kidney. Congruously, $20 \mathrm{mg} / \mathrm{kg}$ maslinic acid treatment upregulated the activities of enzymes targeting reactive oxygen species, including MnSOD, GSH and CAT (Fig. 5c, d and e). Thus, one of the possible mechanisms by which maslinic acid protected the renal tissue of diabetic mice was to reduce the oxidative pressure of the kidney.

\section{Effects of maslinic acid treatment on renal inflammation.}

The inflammatory factors including IL-6, MCP-1 and TNF- $a$ in renual tissue and serum of mice in different groups was evaluated by ELISA and qRT-PCR assay. The renal IL-6, MCP-1 and TNF-a increased with STZ induction, and $20 \mathrm{mg} / \mathrm{kg}$ maslinic acid treatment lowered these pro-inflammatory cytokines in renal tissues dramatically (Fig. 6a, b and c). Congruously, the circulating levels of pro-inflammatory cytokines including IL-6, MCP-1 and TNF-a were also decreased with the treatment of maslinic acid in diabetic mice (Fig. 6d, e and f), suggesting that maslinic acid inhibited the inflammation during the progression of diabetic nephropathy.

\section{Maslinic acid treatment activated renal AMPK/SIRT1 signaling pathway.}

To further demonstrate the molecular mechanisms of the nephropathy effect of maslinic acid, Westernblotting assay was performed. As shown in Fig. 7a and b, maslinic acid treatment induced the phosphorylation of AMPK. The activation of AMPK thus induced the upregulation of SIRT1 (Fig. 7a and c). Since AMPK and SIRT1 play crucial roles in the oxidative protection and anti-inflammatory activity, it is possible that maslinic acid protected the renal function in diabetic mice via activating the AMPK/SIRT1 signaling pathway.

\section{Discussion}

As of 2015 , about 415 million people in the world were suffering from diabetes, and by 2040 this number is expected to increase to 642 million [19]. Diabetic nephropathy is one of the most common complications of diabetes at present [20]. The end-stage renal disease caused by diabetic nephropathy has a very high morbidity and mortality rate worldwide. Mogensen et al. divided the progression of diabetic nephropathy into five stages according to its disease course and pathophysiological process: stage 1 , renal hyperfunction and hypertrophy, and increased urinary albumin excretion; stage 2, no obvious morphological damage and increased glomerular filtration rate (GFR); stage 3 , initiation of diabetic nephropathy, continuous proteinuria, and increased albuminuria and GFR; stage 4, overt diabetic nephropathy, persistent proteinuria $(>0.5 \mathrm{~g} / 24 \mathrm{~h}$ ), decreased GFR caused by high blood pressure; stage 5 , uremic end-stage renal failure due to diabetic nephropathy [21]. Thus, it is urgent for us to explore new 
therapeutic strategies to reverse the damaged renal function in stage 1 and 2 and alleviate the symptoms of diabetic nephropathy in stage 3 and 4 . The pathogenesis of diabetic nephropathy is mainly affected by several factors, including disorders of glucose metabolism, alteration in renal blood flow, abnormal expression of cytokines, genetic factors, elevated blood pressure and abnormal blood lipid levels [22]. Among them, the glucose-metabolism disorder is a core and classic cause of diabetic nephropathy [23]. Kidney is an important metabolic site for advanced glycation end products (AGEs) [24]. Abnormal glucose metabolism in diabetic patients can cause a large accumulation of AGEs and severely damage the kidneys [25]. The deposit of AGEs in the glomerular basement membrane, glomerular mesangial cells, endothelial cells and podocytes will alter the structure of the glomerular basement membrane, cause abnormal filtration membrane function, significantly increase extracellular matrix, and ultimately lead to glomerular sclerosis and proteinuria $[26,27]$. Thus, it is crucial for clinicians to identify agents with both nephroprotective effects and metabolic regulatory functions to treat the diabetic nephropathy.

In this study, we reported that maslinic acid was a new agent for the treatment of diabetic nephropathy with compound effects. First of all, maslinic acid itself had the effect of regulating blood glucose levels and improving the systemic metabolism of diabetic mice. The hypoglycemic effect of maslinic acid could reduce the deposition of AGEs in the kidneys of diabetic mice, thereby protecting kidney function. Secondly, maslinic acid could further protect the kidney function of diabetic mice by reducing the oxidative pressure and inflammation in the kidney area of mice induced by STZ. Compared with other traditional medicines, maslinic acid had multiple protective effects on kidney function, which made it more advantageous in the treatment of diabetic nephropathy.

Maslinic acid belongs to the class of triterpene acids and is a derivative of oleanolic acid. Maslinic acid can significantly resist the elevation of blood glucose level caused by adrenaline and glucose and the degradation of liver glycogen caused by adrenaline [28]. Maslinic acid increases liver glycogen content in mice with glucose-induced hyperglycemia, and can increase liver glycogen reserves in normal mice without affecting normal blood sugar levels [29]. A previous research shows that maslinic acid, a natural ingredient extracted from olive oil, has obvious antioxidant properties in cultured cells in vitro [30]. It has also been reported that maslinic acid inhibits the expression of arterial inducible nitric oxide ribozyme (iNOS) gene in the mouse peritoneal macrophage with the induction of lipopolysaccharide (LPS) [31], suggesting the strong anti-inflammation effects of maslinic acid. Scientists at the University of Granada in Spain found that maslinic acid can inhibit the activation of serine proteases, by which HIV can release itself from the infected cells to the outside and spread to the body of the virus-infected person [32]. Thus, maslinic acid can reduce the spread of HIV in the body by 80 percent. In addition to being widely recognized for its antioxidant, anti-inflammatory, antibacterial and antiviral abilities, maslinic acid has also been proven to have anti-diabetic effects by some studies. For instance, Hung et. al demonstrated that maslinic acid played an important role in the protection of cardiovascular systems in diabetic mice when administrated with Asiatic acid [16]. In addition, maslinic acid has been reported to enhance the insulin signaling pathway and inhibit glycogen phosphorylase to regulate glycogen metabolism [33]. Similarly, we also reported the anti-diabetic effects of maslinic acid in this article. We showed that 20 $\mathrm{mg} / \mathrm{kg}$ maslinic acid treatment effectively reduced the blood sugar content of diabetic mice for about 8 
weeks. We also proved that maslinic acid could inhibit the inflammatory response and oxidative stress of specific tissues, which was consistent with the results of previous studies.

AMPK is an important energy sensor, which can sense the energy metabolism state in the body and regulate the energy metabolism process by altering the gene expression or activity of its downstream molecules [34]. AMPK can transcriptionally activate Nicotinamide phosphoribosyl transferase (Nampt), which increases the ratio of NAD+/NADH and activates another energy sensor, Sirt1. The activation of AMPK and Sirt1 strengthens the body's catabolism and weakens the anabolism, assisting to reduce blood glucose levels and maintain the homeostasis of metabolism [18]. Insulin resistance plays an important role in the pathogenesis of diabetic nephropathy. In insulin-resistant organs, AMPK pathway activation can increase insulin sensitivity. The specific mechanism is related to the inhibition of mTOR/p70S6K pathway [35]. In this study, we demonstrated for the first time that the treatment of maslinic acid can effectively promote the phosphorylation of AMPK in the kidney tissue of diabetic mice. The activation of AMPK further up-regulated the expression of SIRT1. The activation of AMPK/SIRT1 signaling pathway effectively regulates the metabolism in the kidney of diabetic mice, thereby protecting the renal function and alleviating the symptoms of diabetic nephropathy.

\section{Conclusions}

In conclusion, we reported that maslinic acid administration alleviated the diabetic nephropathy in mouse model by activating AMPK/SIRT1 signaling pathway. Maslinic acid treatment can not only reduce the blood sugar level of diabetic mice, but also reduce the oxidative stress and inflammation in their kidneys. Therefore, maslinic acid treatment can protect the structure and function of the kidney in diabetic mice. We believe that our research could provide new evidence for the application maslinic acid in clinic.

\section{Abbreviations}

CKD: chronic kidney disease

ESRD: end-stage renal disease

AMP: Adenosine 5'-monophosphate

AMPK: activated protein kinase

STZ: Streptozocin

MA5: diabetic mice treated with $5 \mathrm{mg} / \mathrm{kg}$ maslinic acid

MA10: diabetic mice treated with $10 \mathrm{mg} / \mathrm{kg}$ maslinic acid

MA20: diabetic mice treated with $20 \mathrm{mg} / \mathrm{kg}$ maslinic acid 
BUN: blood urea nitrogen

MDA: malondialdehyde

ROS: Reactive oxygen species

MnSOD: Manganese superoxide dismutase

GSH: glutathione

GFR: glomerular filtration rate

AGEs: advanced glycation end products

iNOS: inducible nitric oxide ribozyme

LPS: lipopolysaccharide

\section{Declarations}

\section{Funding}

No funding was received for conducting this study.

\section{Conflicts of interest/Competing interests}

The authors declare that they have no known conflicts of interest

\section{Availability of data and material}

The datasets supporting the results of this article are included within the article.

\section{Code availability}

Not applicable

\section{Authors' contributions}

Hong Wu designed and supervised the study. Huijuan Gao performed experiments and analysed data. Huijuan Gao and Hong Wu wrote the manuscript and manuscript revisions. All authors reviewed the results and approved the final version of the manuscript.

\section{Ethics approval}

The methods were performed in accordance with the relevant guidelines of the institutional animal care and use committee of Daqing Oilfield General Hospital. The study was reported in accordance with ARRIVE guidelines. 


\section{Consent to participate}

Not applicable

\section{Consent for publication}

All authors reviewed the results and approved the final version of the manuscript.

\section{References}

1. Massolini BD, Contieri SSG, Lazarini GS, Bellacosa PA, Dobre M, Petroianu G, Brateanu A, Campos LA, Baltatu OC: Therapeutic Renin Inhibition in Diabetic Nephropathy-A Review of the Physiological Evidence. Front Physiol 2020, 11:190.

2. Vlachou E, Ntikoudi A, Govina O, Lavdaniti M, Kotsalas N, Tsartsalis A, Dimitriadis G: Effects of Probiotics on Diabetic Nephropathy: A Systematic Review. Curr Clin Pharmacol 2020.

3. Wang H, Zhuang Z, Huang YY, Zhuang ZZ, Jin Y, Ye HY, Lin XJ, Zheng Q, Wang YL: Protective Effect and Possible Mechanisms of Astragaloside IV in Animal Models of Diabetic Nephropathy: A Preclinical Systematic Review and Meta-Analysis. Front Pharmacol 2020, 11:988.

4. Ishibashi M, Shiiyama R: A Case of Psoriasis Vulgaris Treated with Brodalumab in a Hemodialysis Patient with End-Stage Renal Disease due to Diabetic Nephropathy. Case Rep Dermatol Med 2020, 2020:3863152.

5. Misra PS, Szeto SG, Krizova A, Gilbert RE, Yuen DA: Renal histology in diabetic nephropathy predicts progression to end-stage kidney disease but not the rate of renal function decline. BMC Nephrol 2020, 21(1):285.

6. Lanthier L, Huard G, Plourde ME, Cauchon M: [In patients with type 2 diabetes and diabetic nephropathy with albuminuria, what is the effect of SGLT2 inhibitor canagliflozin on renal and cardiovascular outcomes?]. Rev Med Interne 2020, 41(1):67-68.

7. Morimoto K, Matsui M, Samejima K, Kanki T, Nishimoto M, Tanabe K, Murashima M, Eriguchi M, Akai $\mathrm{Y}$, Iwano $\mathrm{M}$ et al: Renal arteriolar hyalinosis, not intimal thickening in large arteries, is associated with cardiovascular events in people with biopsy-proven diabetic nephropathy. Diabet Med 2020.

8. Wei Q, Zhang B, Li P, Wen X, Yang J: Maslinic Acid Inhibits Colon Tumorigenesis by the AMPK-mTOR Signaling Pathway. J Agric Food Chem 2019, 67(15):4259-4272.

9. Nagai N, Yagyu S, Hata A, Nirengi S, Kotani K, Moritani T, Sakane N: Maslinic acid derived from olive fruit in combination with resistance training improves muscle mass and mobility functions in the elderly. J Clin Biochem Nutr 2019, 64(3):224-230.

10. Pavel IZ, Csuk R, Danciu C, Avram S, Baderca F, Cioca A, Moaca EA, Mihali CV, Pinzaru I, Muntean DM et al: Assessment of the Antiangiogenic and Anti-Inflammatory Properties of a Maslinic Acid Derivative and its Potentiation using Zinc Chloride. Int J Mol Sci 2019, 20(11). 
11. Shimazu K, Fukumitsu S, Ishijima T, Toyoda T, Nakai Y, Abe K, Aida K, Okada S, Hino A: The AntiArthritis Effect of Olive-Derived Maslinic Acid in Mice is Due to its Promotion of Tissue Formation and its Anti-Inflammatory Effects. Mol Nutr Food Res 2019, 63(3):e1800543.

12. Rufino-Palomares EE, Reyes-Zurita FJ, Garcia-Salguero L, Mokhtari K, Medina PP, Lupianez JA, Peragon J: Maslinic acid, a triterpenic anti-tumoural agent, interferes with cytoskeleton protein expression in HT29 human colon-cancer cells. J Proteomics 2013, 83:15-25.

13. Mkhwanazi BN, van Heerden FR, Mavondo GA, Mabandla MV, Musabayane CT: Triterpene derivative improves the renal function of streptozotocin-induced diabetic rats: a follow-up study on maslinic acid. Ren Fail 2019, 41(1):547-554.

14. Thakor P, Song W, Subramanian RB, Thakkar VR, Vesey DA, Gobe GC: Maslinic Acid Inhibits Proliferation of Renal Cell Carcinoma Cell Lines and Suppresses Angiogenesis of Endothelial Cells. $J$ Kidney Cancer VHL 2017, 4(1):16-24.

15. Mkhwanazi BN, Serumula MR, Myburg RB, Van Heerden FR, Musabayane CT: Antioxidant effects of maslinic acid in livers, hearts and kidneys of streptozotocin-induced diabetic rats: effects on kidney function. Ren Fail 2014, 36(3):419-431.

16. Hung YC, Yang HT, Yin MC: Asiatic acid and maslinic acid protected heart via anti-glycative and anticoagulatory activities in diabetic mice. Food Funct 2015, 6(9):2967-2974.

17. Xu W, Wang L, Li J, Cai Y, Xue Y: TXNIP mediated the oxidative stress response in glomerular mesangial cells partially through AMPK pathway. Biomed Pharmacother 2018, 107:785-792.

18. Behrouz V, Dastkhosh A, Hedayati M, Sedaghat M, Sharafkhah M, Sohrab G: The effect of crocin supplementation on glycemic control, insulin resistance and active AMPK levels in patients with type 2 diabetes: a pilot study. Diabetol Metab Syndr 2020, 12:59.

19. Diaz-Valencia PA, Bougneres P, Valleron AJ: Global epidemiology of type 1 diabetes in young adults and adults: a systematic review. BMC Public Health 2015, 15:255.

20. Sumida Y, Yoneda M, Toyoda H, Yasuda S, Tada T, Hayashi H, Nishigaki Y, Suzuki Y, Naiki T, Morishita A et al: Common Drug Pipelines for the Treatment of Diabetic Nephropathy and Hepatopathy: Can We Kill Two Birds with One Stone? Int J Mol Sci 2020, 21(14).

21. Mogensen $C E$, Christensen CK, Vittinghus E: The stages in diabetic renal disease. With emphasis on the stage of incipient diabetic nephropathy. Diabetes 1983, 32 Suppl 2:64-78.

22. Haraguchi R, Kohara Y, Matsubayashi K, Kitazawa R, Kitazawa S: New Insights into the Pathogenesis of Diabetic Nephropathy: Proximal Renal Tubules Are Primary Target of Oxidative Stress in Diabetic Kidney. Acta Histochem Cytochem 2020, 53(2):21-31.

23. Miyata T, de Strihou C: Diabetic nephropathy: a disorder of oxygen metabolism? Nat Rev Nephrol 2010, 6(2):83-95.

24. Kopytek M, Zabczyk M, Mazur P, Undas A, Natorska J: Accumulation of advanced glycation end products (AGEs) is associated with the severity of aortic stenosis in patients with concomitant type 2 diabetes. Cardiovasc Diabetol 2020, 19(1):92. 
25. Chen Y, Jiao N, Jiang M, Liu L, Zhu Y, Wu H, Chen J, Fu Y, Du Q, Xu H et al: Loganin alleviates testicular damage and germ cell apoptosis induced by AGEs upon diabetes mellitus by suppressing the RAGE/p38MAPK/NF-kappaB pathway. J Cell Mol Med 2020, 24(11):6083-6095.

26. Chen Q, Huang J, Gong W, Chen Z, Huang J, Liu P, Huang H: MRTF-A mediated FN and ICAM-1 expression in AGEs-induced rat glomerular mesangial cells via activating STAT5. Mol Cell Endocrinol 2018, 460:123-133.

27. Huang K, Chen C, Hao J, Huang J, Wang S, Liu P, Huang H: Polydatin promotes Nrf2-ARE antioxidative pathway through activating Sirt1 to resist AGEs-induced upregulation of fibronetin and transforming growth factor-beta1 in rat glomerular messangial cells. Mol Cell Endocrinol 2015, 399:178-189.

28. Liu J, Wang X, Chen YP, Mao LF, Shang J, Sun HB, Zhang LY: Maslinic acid modulates glycogen metabolism by enhancing the insulin signaling pathway and inhibiting glycogen phosphorylase. Chin J Nat Med 2014, 12(4):259-265.

29. Guan T, Li Y, Sun H, Tang X, Qian Y: Effects of maslinic acid, a natural triterpene, on glycogen metabolism in cultured cortical astrocytes. Planta Med 2009, 75(10):1141-1143.

30. Guan T, Qian Y, Tang X, Huang M, Huang L, Li Y, Sun H: Maslinic acid, a natural inhibitor of glycogen phosphorylase, reduces cerebral ischemic injury in hyperglycemic rats by GLT-1 up-regulation. $J$ Neurosci Res 2011, 89(11):1829-1839.

31. Lee W, Kim J, Park EK, Bae JS: Maslinic Acid Ameliorates Inflammation via the Downregulation of NF-kappaB and STAT-1. Antioxidants (Basel) 2020, 9(2).

32. Parra A, Rivas F, Lopez PE, Garcia-Granados A, Martinez A, Albericio F, Marquez N, Munoz E: Solutionand solid-phase synthesis and anti-HIV activity of maslinic acid derivatives containing amino acids and peptides. Bioorg Med Chem 2009, 17(3):1139-1145.

33. Wen X, Zhang P, Liu J, Zhang L, Wu X, Ni P, Sun H: Pentacyclic triterpenes. Part 2: Synthesis and biological evaluation of maslinic acid derivatives as glycogen phosphorylase inhibitors. Bioorg Med Chem Lett 2006, 16(3):722-726.

34. Zhang XQ, Zhao D, Ma YD, Wang YC, Zhang LX, Guo WJ, Zhang JH, Nie L, Yue LM: Impact of Disturbed Glucose Homeostasis Regulated by AMPK in Endometrium on Embryo Implantation in Diabetes Mice. Reprod Sci 2020.

35. Wang Y, Rijal B, Xu M, Li Z, An Y, Zhang F, Lu C: Renal denervation improves vascular endothelial dysfunction by inducing autophagy via AMPK/mTOR signaling activation in a rat model of type 2 diabetes mellitus with insulin resistance. Acta Diabeto/ 2020.

\section{Figures}



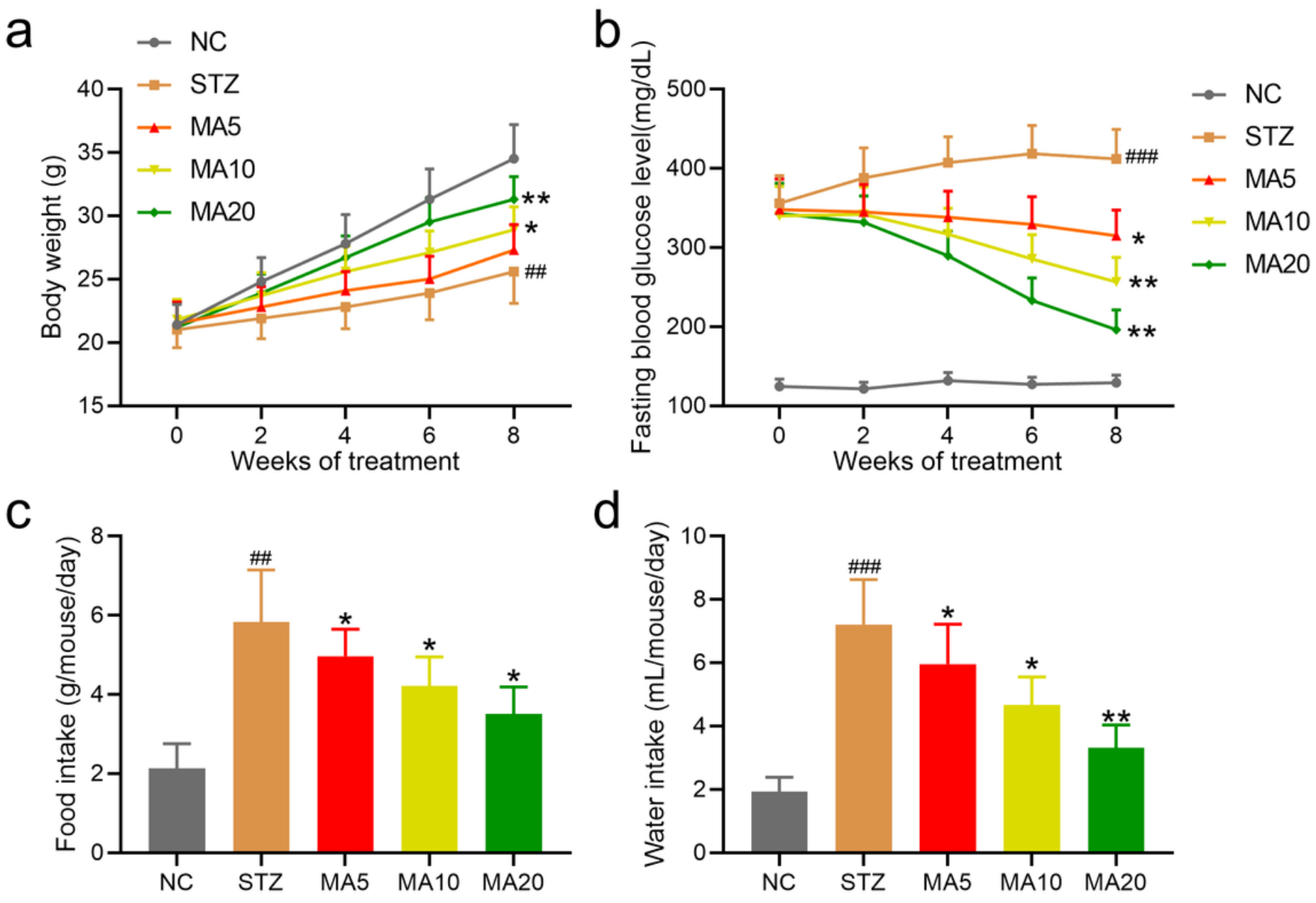

Figure 1

Effects of maslinic acid treatment on body weight (a), fasting blood glucose levels (b), average food intake (c) and average water intake (d) in mice model of diabetic nephropathy. All mice had free access to food and water at all times. The volume of consumed water and amount of food were recorded. Fasting blood glucose levels and body weight were measured once every 2 weeks for 8 weeks. $N=14$ for each group. Data are presented as mean \pm SD. \#\#p $<0.01$, \#\#\#p $<0.001$ compared to NC group, ${ }^{\star} p<0.05,{ }^{* \star} p$ $<0.01$ compared to STZ group. 

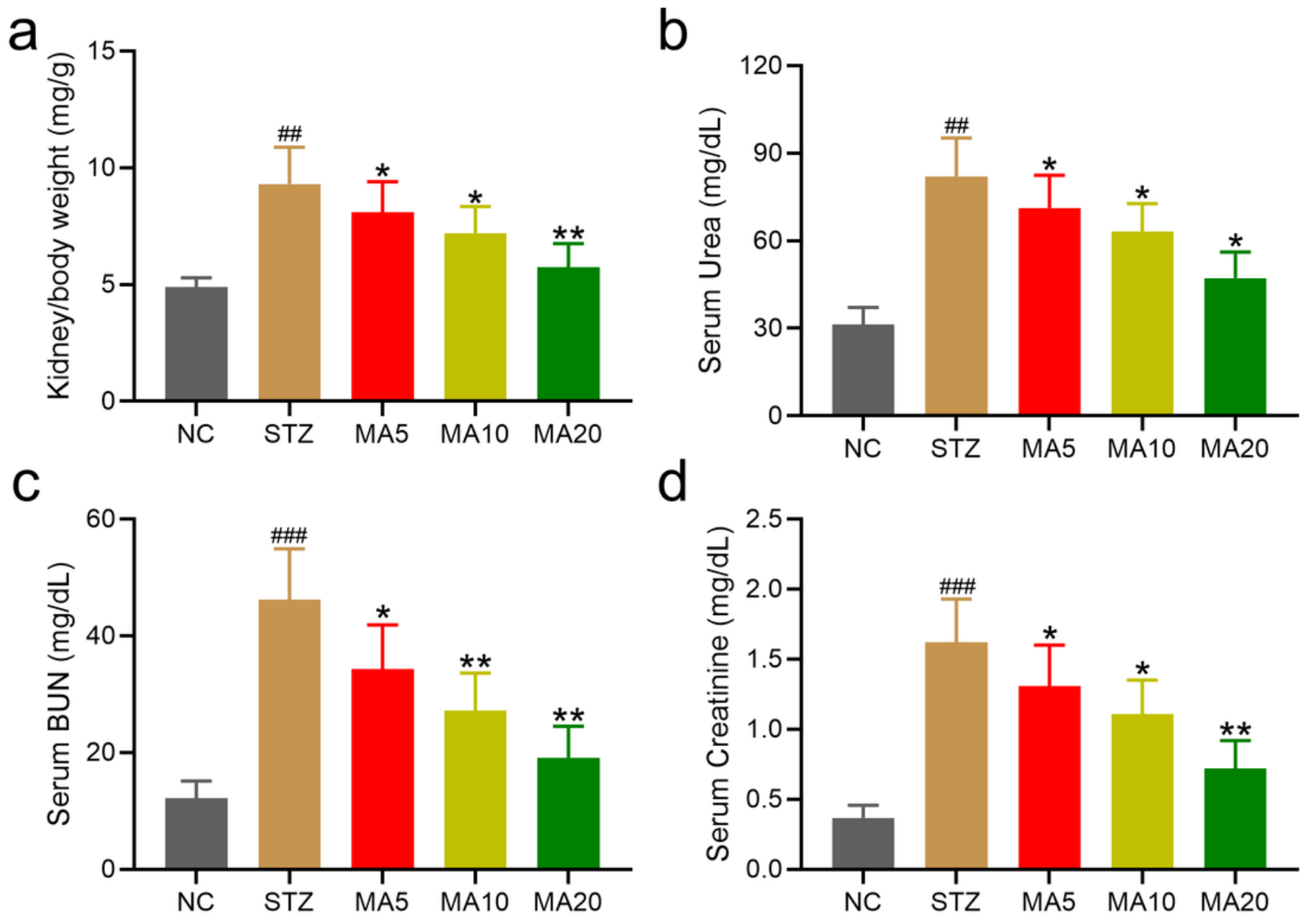

d

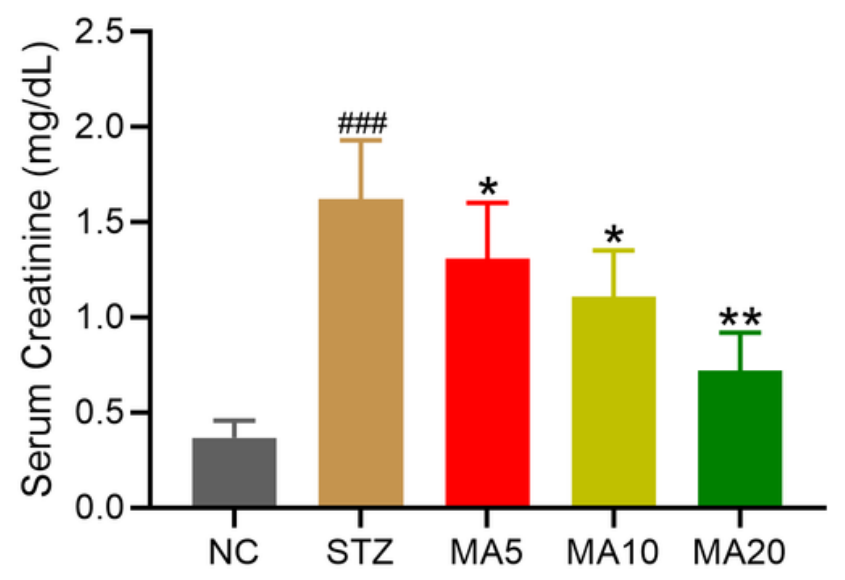

Figure 2

Effects of maslinic acid treatment on kidney/body weight (a), Urea (b), BUN (c) and Creatinine (d) in serum of mice model of diabetic nephropathy at the end of 8-week treatment. Serum levels of blood urea nitrogen (BUN), urea, and creatinine ( $\mathrm{Cr}$ ) were analyzed by an automatic analyzer (cobas ${ }^{\circledR} 8,000$ modular analyzer series. Roche Diagnostics). $\mathrm{N}=14$ for each group. Data are presented as mean $\pm \mathrm{SD}$. \#\#p $<0.01$, \#\#\#p $<0.001$ compared to NC group, ${ }^{\star} p<0.05,{ }^{\star \star} \mathrm{p}<0.01$ compared to STZ group. 

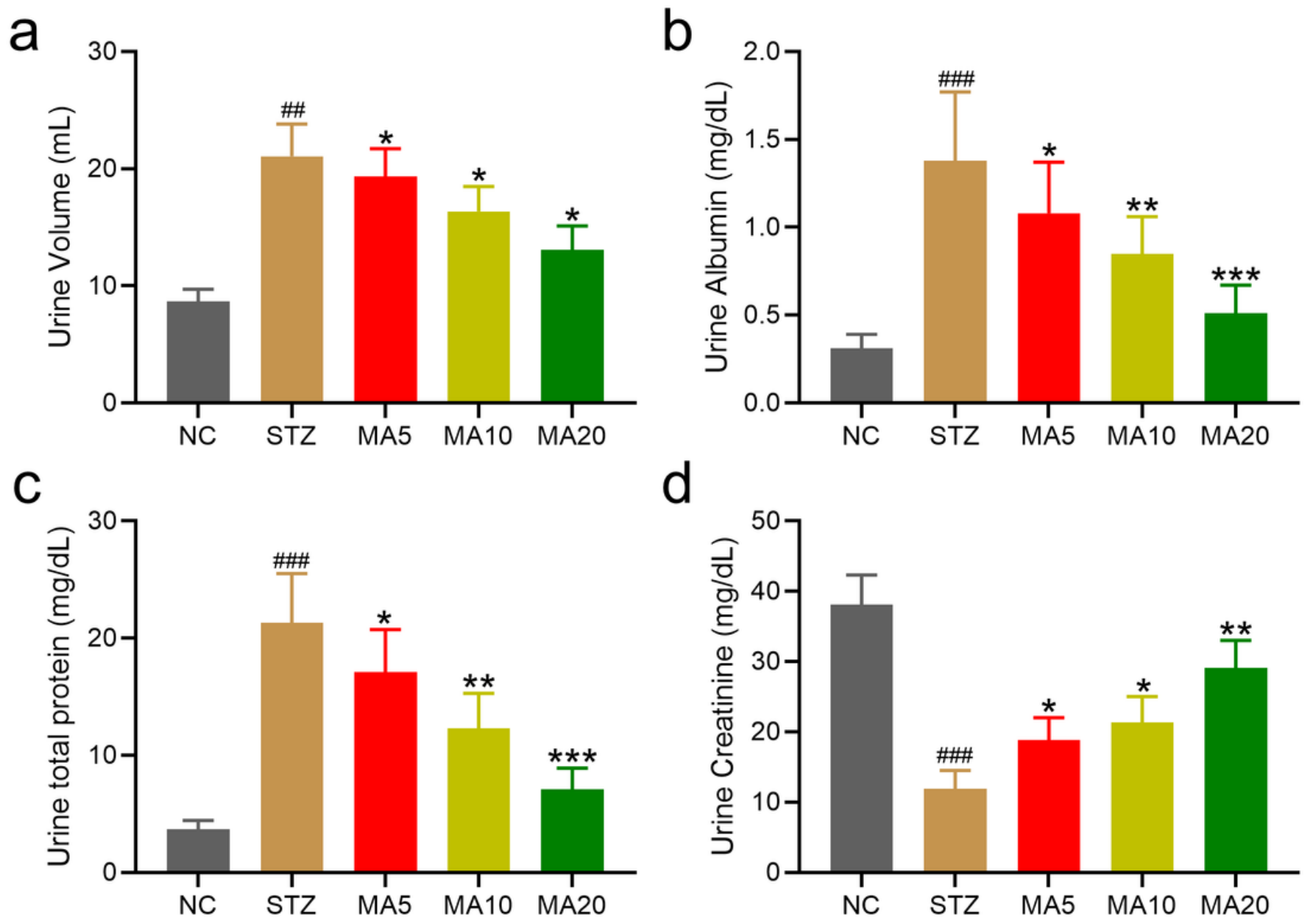

Figure 3

Effects of maslinic acid treatment on urine volume (a), urine albumin (b), total proteins (c) and Creatinine (d) in urine of mice model of diabetic nephropathy at the end of 8-week treatment. Urinary levels of albumin, total proteins, and creatinine were analyzed by an automatic analyzer (cobas $₫ 8,000$ modular analyzer series. Roche Diagnostics). $\mathrm{N}=14$ for each group. Data are presented as mean $\pm \mathrm{SD}$. \#\#p $<0.01$, $\# \# \# p<0.001$ compared to NC group, ${ }^{\star} p<0.05$, ${ }^{\star \star} p<0.01$ and ${ }^{\star \star \star} p<<0.001$ compared to STZ group. 
a

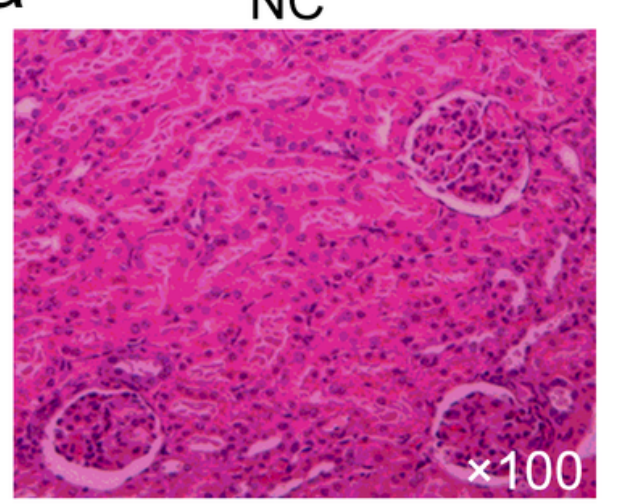

STZ

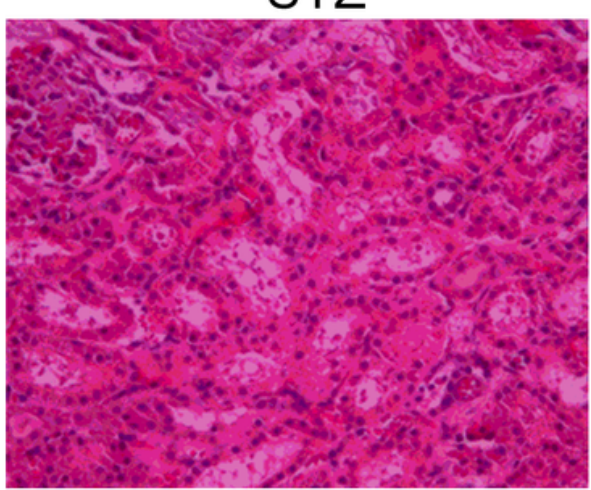

MA20

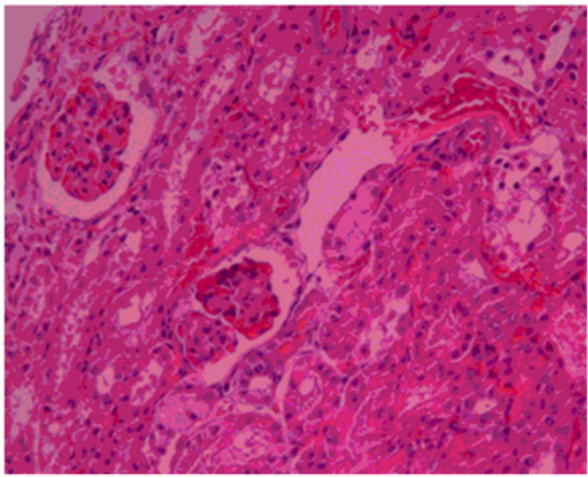

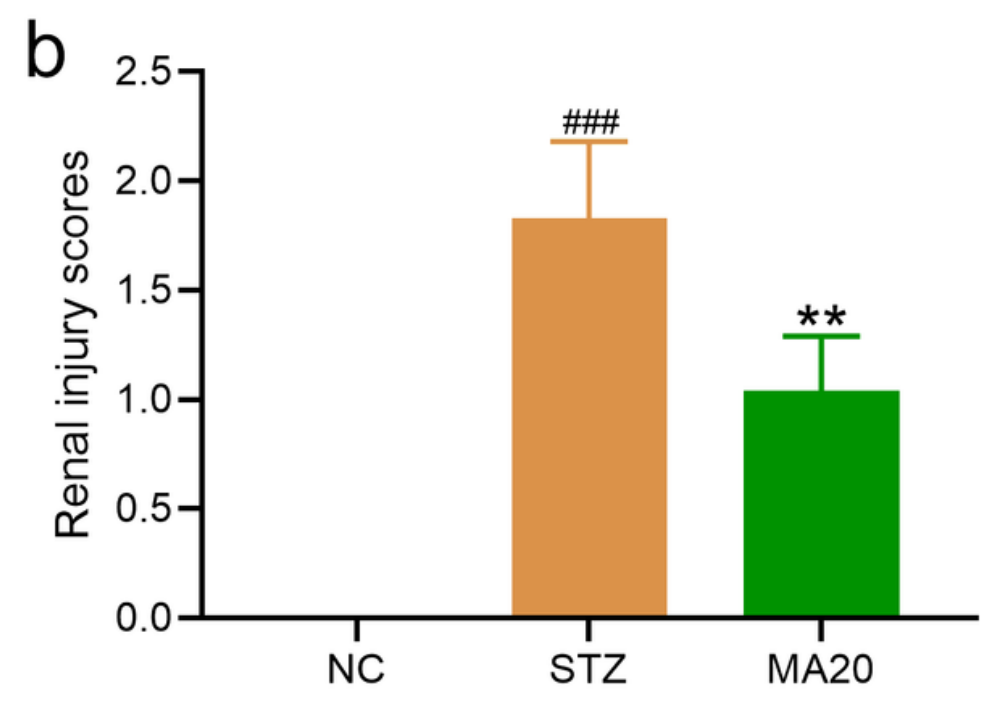

Figure 4

Effects of $20 \mathrm{mg} / \mathrm{kg}$ maslinic acid treatment for 8 weeks on renal injury in mice model of diabetic nephropathy. a) Representative image of renal tissue stained with hematoxylin and eosin (HE) and the quantification of renal injury score (b). $\mathrm{N}=10$ for each group. Data are presented as mean $\pm \mathrm{SD}$. \#\#\#p< 0.001 compared to NC group, ${ }^{\star \star} p<0.01$ compared to STZ group. 

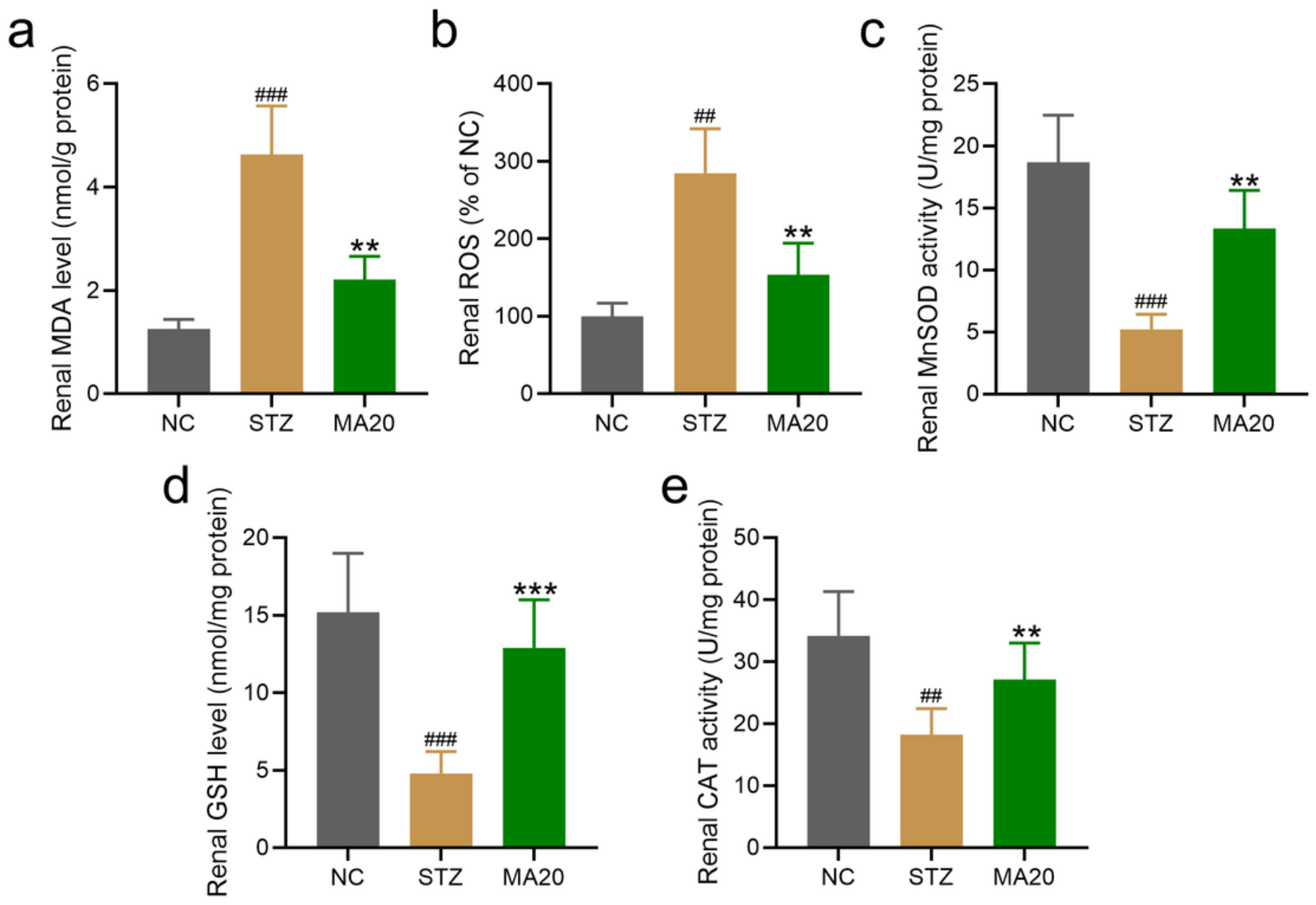

Figure 5

Effects of $20 \mathrm{mg} / \mathrm{kg}$ maslinic acid treatment for 8 weeks on renal oxidative stresses in mice model of diabetic nephropathy. The levels of MDA (a), ROS (b), MnSOD (c), GSH (d) and CAT (e) in renal tissues were measured. $\mathrm{N}=8$ for each group. Data are presented as mean $\pm \mathrm{SD}$. \#\#p $<0.01, \# \# \# p<0.001$ compared to NC group, ${ }^{\star \star} p<0.01$ and ${ }^{\star \star \star} p<0.001$ compared to STZ group. 

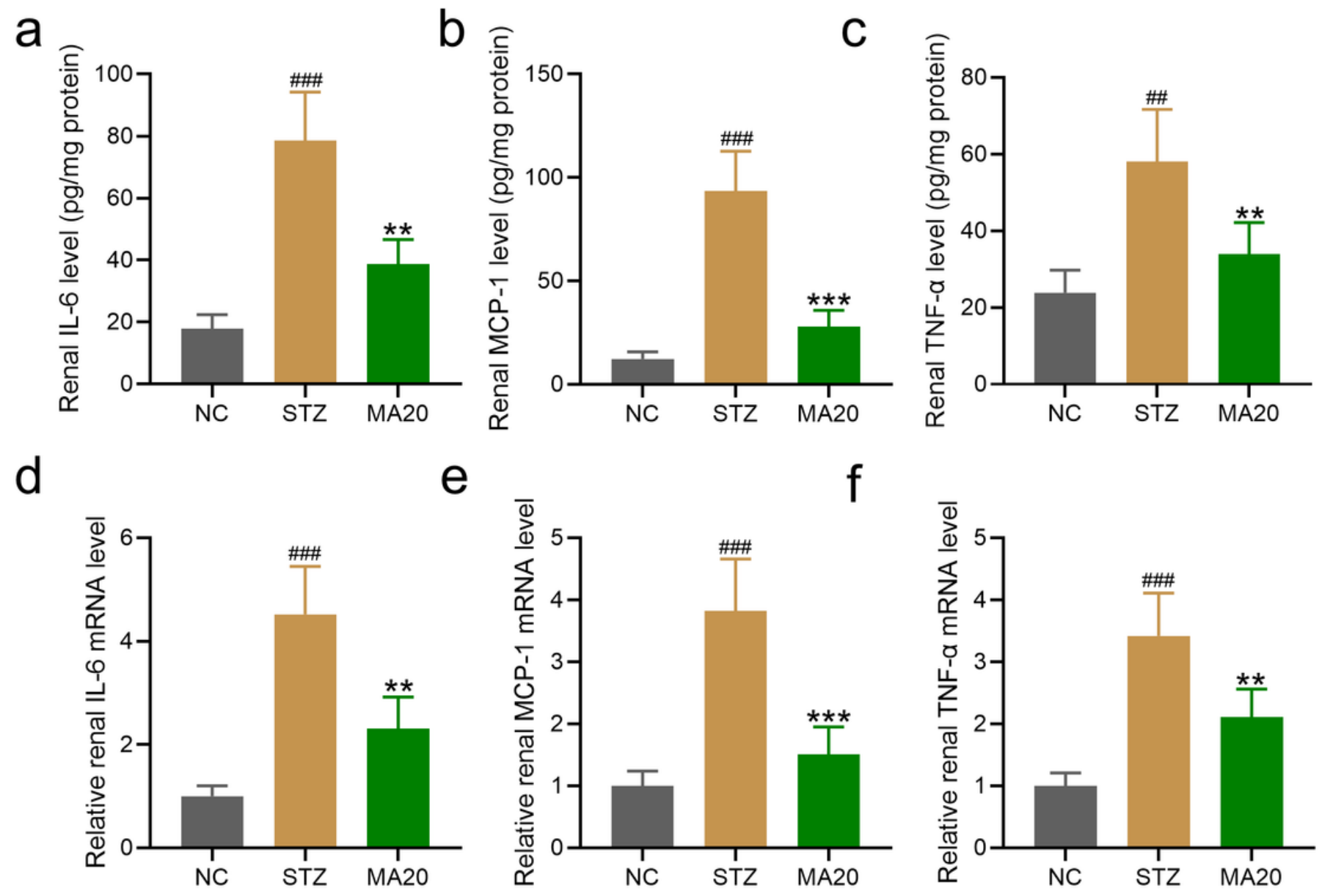

Figure 6

Effects of $20 \mathrm{mg} / \mathrm{kg}$ maslinic acid treatment for 8 weeks on renal inflammatory responses in mice model of diabetic nephropathy. Levels of IL-6 (a), MCP-1 (b) and TNF- $a$ (c) in the renal tissues of diabetic nephropathy mice. mRNA levels of IL-6 (d), MCP-1 (e) and TNF-a (f) in the renal tissues were tested by qRT-PCR. Relative expression pattern was analyzed by comparative threshold cycle (2- $\Delta \Delta \mathrm{ct})$ method and normalized to NC group. $\mathrm{N}=10$ for each group. Data are presented as mean $\pm \mathrm{SD}$. \#\#p $<0.01, \# \# \# p<$ 0.001 compared to NC group, ${ }^{\star \star} p<0.01$ and ${ }^{\star \star \star} \mathrm{p}<0.001$ compared to STZ group. 

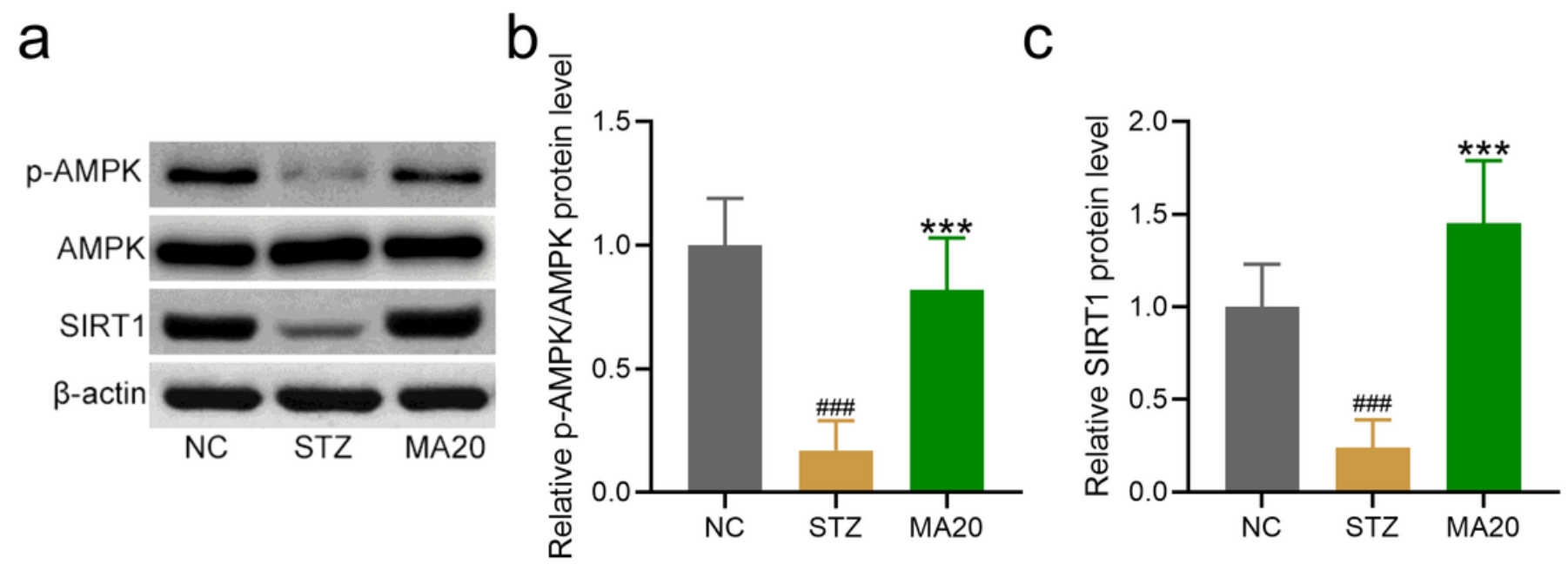

Figure 7

Maslinic acid treatment for 8 weeks activated renal AMPK/SIRT1 signaling pathway in mice model of diabetic nephropathy. Western blotting was used to measure the protein expressions of p-AMPK, AMPK and SIRT1 (a) and the relative expressions were normalized to NC. N=10 for each group. Data are presented as mean \pm SD. \#\#\#p $<0.001$ compared to NC group, ${ }^{\star \star \star} p<0.001$ compared to STZ group. 